\title{
Raising awareness about birth control
}

\author{
Haley Gabel and Claire Snowden
}

\section{Abstract}

The socio-scientific issue that we studied was methods of birth control and how they may be influenced by political, ethical and religious controversies. In our study we uncovered how much knowledge an average person has about such a common and crucial issue. We concluded, based on our mini study, that $74 \%$ of high school students attending Catholic school in 2012 did not receive any education about methods of birth control. In addition, $85 \%$ of the general public that we surveyed are supporters of birth control. We feel that young people need more education about birth control. We would like to spread awareness about primary types of birth control methods. We wrote letters to six popular teenage and young adult magazines. We also created a video featuring an interview with our health education teacher, which we posted to YouTubeTM with her permission. Educating youth can help change the rates of teenage pregnancy and avoid any unnecessary controversy about emergency methods such as abortion. 


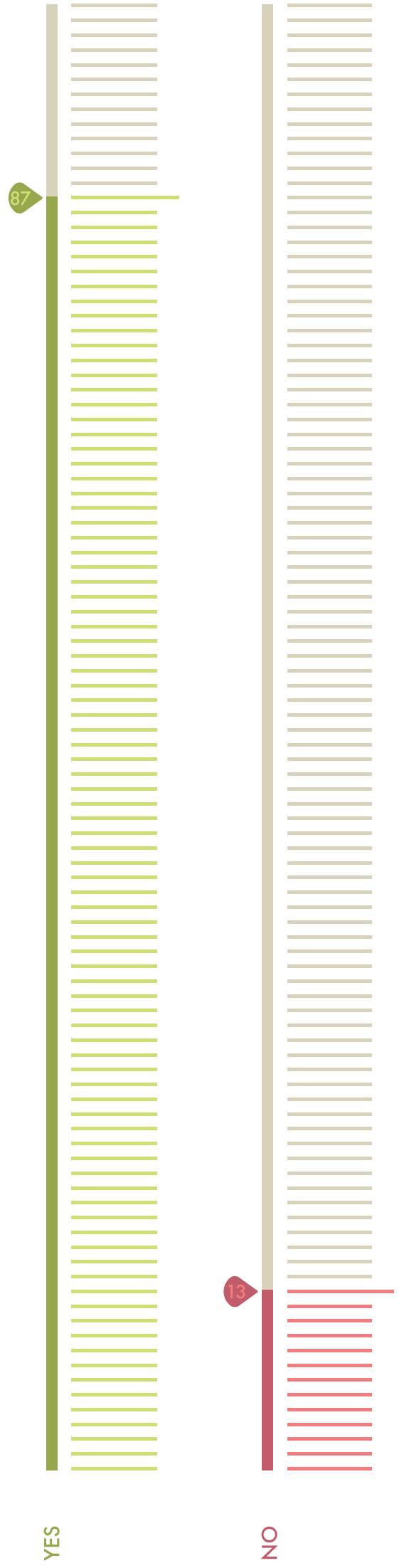

Figure 1: Are you in support of Birth Control?

\section{Introduction}

Birth control is an ongoing issue in today's society. The controversy is mainly surrounds the use of emergency birth control known as Plan B and abortion. The knowledge about primary types of birth control to avoid the use of emergency methods should be known by teenagers and young adults. If teenagers and young adults are aware of the methods provided and the possible effects on their body, then they will make wiser choices.

Birth control is successful in preventing unwanted pregnancies and some may also protect against sexually transmitted infections (STIs) for both partners. The most common methods of birth control are male condoms and the pill. One of the issue may be that the users of birth control are not properly educated on how to use the birth control method. This may result in possible unwanted outcomes. The pill, and the patch, are both hormonal methods of birth control. They alter the female ovulation cycle to make it more challenging for the egg to be fertilized. They are not guaranteed and they do not offer protections against STIs. A safer and more reliable way to prevent pregnancy and STIs is by using a combination of hormonal and barrier birth control (male or female condoms). The issue is that this information is not as common knowledge as it should be, which may be surprising to some.

By raising more awareness about birth control methods, less teenage pregnancies will occur and the spread of sexually transmitted infections could be lessened. This would have a positive impact on individuals and society. The government, 'pro life' organizations and 'pro choice' organizations are powerful stakeholders in this controversy. We are encouraging the side that it is up to the individuals to decide what to do with their body. However, individuals need to be educated when making decisions, especially decisions that may leave them with unwanted consequences.

\section{Focus of our Study}

The goal of our study was to identify any relationships in opinions between females and males, different generations, different religions, and how informed the average person is on different methods of birth control. On Saturday May 25th, 2012, we walked around Square One mall from 11:00 AM to 3:00PM and surveyed 50 girls (ages 13-19), 50 boys (ages 13-19), 50 women (ages 20 and up) and 50 men (ages 20 and up). We used a survey App on an iPad to accurately record our results.

We asked the following questions:

- Are you Male or Female?

- Are you Teenager (13-19) or Adult (20 and up)?

- Were you educated at a Public school or Catholic school?

- How many different types of birth control methods can you name?

- Are you a supporter of birth control methods (hormonal, barrier, emergency)? 
- Have you ever used any type of birth control methods?

- Have you been educated on different methods of birth control through school?

- Are you religious? If so what religion?

For the purpose of this publication we will report results for only a few of the questions above. However, we will discuss the results of other questions more broadly in the 'summary of results' and 'discussion' sections of this report.

\section{Summary of Results}

We learned that approximately $85 \%$ of the people that we surveyed were in support of birth control (see Figure 1) that approximately half of those individuals used birth control (see Figure 2). However, we cannot tell if the other half of the people were not using birth control or if they were simply not sexually active. Furthermore, most participants (approximately 70\%) who attended Catholic schools reported that they were not educated about birth control in school. Regarding one's knowledge of birth control methods, on average, females can name four different types of birth control and males can name three. As we were conducting the study, we also observed that the topic of birth control is still very taboo. Not many people were comfortable talking about it. We found this surprising considering it is a responsibility placed on millions of young adults everyday.

\section{Discussion}

The most prominent discovery for us about the topic of birth control is that it is still extremely taboo. The controversy between religious, political and ethical groups is continuously growing. From our secondary research we came across websites and blogs for young women asking about methods of birth control. If birth control was more openly discussed in school and at home, we believe that we could help further prevent the spread of STIs, unplanned pregnancies and abortions.

In our survey, we found that girls in general knew more about birth control; however, we feel that the knowledge should be equal between both genders, because it is both partners' responsibility to make sure they are safe if they decide to be sexually active. With growing teen pregnancy rates and media sharing their stories on shows such as Teen Mom or 16 and Pregnant it is important that teenagers and young adults are not influenced by the publicity these girls are receiving. Had the girls in these popular shows been educated about safe sex (or abstinence for that matter), they could have altered the outcome of their unplanned pregnancies.

Our hope is that accessing birth control will eventually become as simple and easy as getting cough medicine at a drugstore. Whether or not people want to take advantage of its availability is out of our control, but the options should be there.

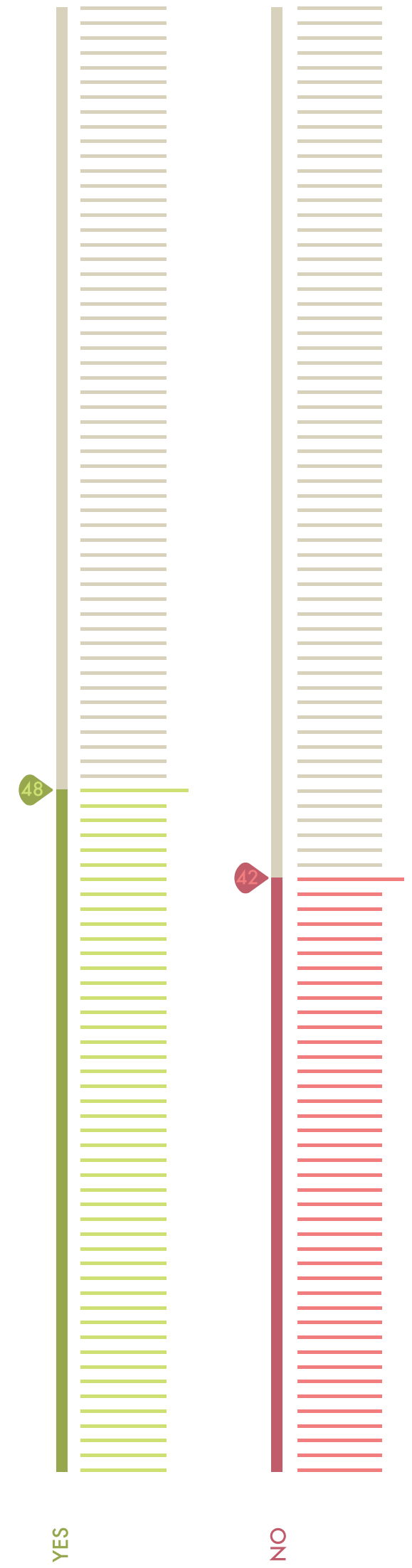

Figure 2: Have you ever used any methods of birth control? 


\section{Taking action}

Our actions were to write to popular teenage and young adult magazines about the importance of this issue. We ask that they highlight methods of birth control in their upcoming magazine issue. This will spread information to the audience of young women who may not feel comfortable openly talking about birth control. We hope that spreading the awareness of birth control methods such as the pill, condoms etc. will avoid the possible use of emergency birth control methods (i.e., abortion) which can be harmful to the body.

Another action we took was to interview our school gym/ health teacher. We asked her opinion on how girls in high school react to the information of birth control and shared it with students in our school to help students realize they are not alone. We sent letters and emails to the following magazines: Seventeen Magazine, GL magazine, Teen Vogue, Elle, Vogue and Glitter.

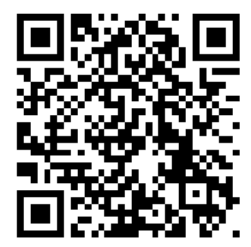

The video can be found here:

http://www.youtube.com/watch? $v=y D$ OSNThiQ1Edefeature=youtu.be

\section{Copy of the letter}

\section{Dear (name of Magazine),}

Our names are Haley Gabel and Claire Snowden. We are grade 10 students at Erindale Secondary School in Mississauga, Canada. Our summative assignment for our Grade 10 Science course consists of selecting a controversial issue that is related to human health and learning more about it through secondary and primary research. Our commitment in these projects is on actions. We decided to write you this letter as part of our action plan to raise awareness about the controversial issue that we studied.

The issue we chose is birth control. We chose a topic that is not typically talked about openly in school andlor home environments. We wanted to learn about the issue and why it is avoided in schools/homes. After conducting on-line research we discovered that there are over 15 types of birth control. The four main types of birth control include the pill, condoms (female and male), the patch, and vaginal rings. Since this was new and surprising information to us, we based our study on surveying the general public about their knowledge and opinion of birth control. We went to a popular Mall in our area and surveyed 50 girls (ages 13-19), 50 boys (ages 13-19), 50 women (ages 20 and up) and 50 men (ages 20 and up). We asked them questions such as:

- Were you educated at a public school, catholic school or a different specialty school?

- How many different types of birth control methods can you name?

- Are you a supporter of birth control methods (barrier, hormonal, emergency)?

- Have you ever used any methods of birth control?

- Have you been educated on different methods of birth control through school?

- Are you religious? If yes, what religion?

After completing our survey and analyzing the data we collected, obvious correlations began to form. It was shocking to us that 74\% of people that attended Catholic schools did not learn about methods of birth control in school. This was surprising because if young women do not have a strong relationship with their parents and they do not learn this information in school, how are they preventing unwanted pregnancies and protecting themselves from STI's?

We also learned that 93\% of people support birth control; however, if the issue is so strongly supported why is it still an awkward topic to bring up? This is why we chose to write a letter to this magazine.

(Title of the magazine) has the power to reach a much larger audience of young women than we ever could on our own. We think it would be a great article in your next issue to break down and simplify birth control in you health section, so that girls can protect themselves and learn reliable information from a trusted source.

Sincerely,

Haley Gabel and Claire Snowden 


\section{References}

Birth control - 15 different methods of contraception and how they work [Video file]. (n.d.). Retrieved from http://www.youtube.com/watch?v=yyaQsjkkKxY

Birth Control Methods - Birth Control Options. (n.d.). Retrieved November 11, 2013, from http://www.plannedparenthood.org/health-topics/birth-control-4211.htm

Birth Control Options | Options for Sexual Health. (n.d.). Retrieved from https://www.optionsforsexualhealth.org/birth-control-pregnancy/birth-control-options

Pappas, S. (2011, November 10). America \& Abortion: Will Controversy Ever Die? | Abortion Debate \& Proposition 26, Personhood | Pro-Choice vs. Pro-Life | LiveScience. Retrieved November 11, 2013, from http://www.livescience.com/16990-abortion-debate-personhood-future.html

Womens Health (n.d.). Birth control methods fact sheet | womenshealth.gov. Retrieved November 11, 2013, from http://www.womenshealth.gov/publications/our-publications/fact-sheet/birth-control-methods.html 